\title{
MODERNIDADE, CULTURA POPULAR E TÁTICAS DE PRESERVAÇÃO NA ALVORADA REPUBLICANA*
}

\author{
Nicolau Sevcenko \\ Depto. de História-FFLCH/USP
}

\section{Resumo}

Com base nas Religiões do Rio, do escritor João do Rio, que conseguiu penetrar para além das fronteiras de sua própria cultura, este artigo mostra como o negro recuperou o segredo do feitiço em posse do branco e renegociou os termos da dominação.

\section{Abstract}

Based on Religiões do Rio, written by João do Rio, this article discusses how he managed to successfuly cross over the boundaries of his own culture, thus being able to witness the way by which the Black communities of Rio de Janeiro regained the spell once stolen by White conquerors, thereby challenging their domination.

\section{Pallavras-Chave}

Negros $\bullet$ Feitiçaria $\bullet$ Religião $\bullet$ Cultura Popular $\bullet$ Rio de Janeiro

\section{Keywords}

Negroes $\bullet$ Witchcraft $\bullet$ Religion $\bullet$ Popular Culture $\bullet$ Rio de Janeiro

\footnotetext{
"Texto originalmente apresentado no Congresso "Profetas de un Nuevo Mundo: vida urbana, modernidad y alteridad en America Latina, 1880-1920", Universidad Mayor de San Marcos, Lima, Peru, julho de 1999
} 
avia uma antiga lenda muito difundida dentre a comunidade de negros Cabindas do Rio de Janeiro na passagem do século. Era uma história aterradora em todos os sentidos. Ela contava sobre um homem branco que apareceu num certo momento em algum lugar em pleno coração da África. Informado, o rei cabinda juntou seus guerreiros, partindo para atacá-lo. Mesmo quando se viu cercado, entretanto, o homem branco não manifestou a menor preocupação. Calmamente, ele tirou um feitiço metálico da cintura e apontando para o babalâ, matou-o num instante, pondo golfadas de sangue pela boca.

- Exu! Exu! Gritou a tribo, recuando de chofre.

- Quem és tu, santo que eu não conheço? Perguntou trêmulo o poderoso rei.

- Sou o que pode tudo, bradou o branco. Vê.

Estendeu a mão de novo e matou outros negros.

- Só te deixarei em paz se me mostrares todos os teus feitiços.

Sua Majestade, apavorada, levou-o à tenda real e durante o dia e durante a noite, sem parar, lhe deu tudo quanto sabia. deixou-a cair, e partiu devagar pela estrada afora... (Rio 1976: 41)

Essa narrativa descreve, numa sequiência de enorme poder simbólico, a representação mítica da queda dos poderosos reinos africanos a partir da conquista européia. Derrotados pela força imbatível dos feitiços metálicos de ogum, dominados pelos brancos, os reinos africanos se vêem, num único lance, despojados de seus líderes espirituais, de seus guerreiros, de seus conhecimentos mágicos e de suas mulheres. O que permite aos brancos a supremacia sem limites: "sou o que pode tudo".

A tragédia da escravidão e do tráfico foi a decorrência natural desse processo de conquista. O translado para o continente americano seria então concebido como a kalunga, a travessia mística que cruzava o limiar entre a ventura e a desfortuna, o prazer e a dor, a vida e a morte (Slenes 1995: 9-11). A intervenção branca invertera o sentido redentor da tradição banto, o que desencadeou uma exacerbação da disposição mística dos contingentes escravos, angustiados para recuperar a trilha da bem- 
aventurança. Do que resultou uma permanente efervescência religiosa dos negros e seus descendentes, muito acentuada pelas maciças migrações para as áreas urbanas após a Abolição em 1888. As cidades permitiam uma melhor organização de altares, templos e fraternidades, além da ampla difusão de amplas redes de práticas clandestinas (Moura 1995: 15-19).

Não que as autoridades não estivessem alertas ou que a Abolição tivesse trazido qualquer sentido de tolerância ou respeito aos homens e mulheres negros e suas tradições culturais. Muito ao contrário. O sentido em que foi conduzida a questão da emancipação servil pelas elites brasileiras, implicou na sua substituição pura e simples pela grande oferta de imigrantes estrangeiros, sobretudo europeus. No projeto da emancipação, não se previu nenhuma forma de integração da população negra no corpo da sociedade brasileira. Vistos como a própria mácula do atraso, o contingente negro foi instantaneamente estigmatizado pela nova elite republicana, a qual assume o poder no ano seguinte à Abolição.

A presença dessa população representava, no novo contexto, a vergonha de um passado arcaico e ossificado, que era preciso eliminar com vistas à entrada na modernidade do século XX, no desfrute de seus novos potenciais tecnológicos e na integração à nova identidade de uma burguesia cosmopolita, de perfil europeizado. É nesse espírito que são conduzidas, por exemplo, as reurbanizações das cidades do Rio de Janeiro, de São Paulo ou do Recife, expulsando as populações negras das áreas centrais, remodeladas conforme a arquitetura eclética de sabor europeu. Os contingentes pobres, basicamente constituídos dos negros ex-escravos e seus descendentes, são empurrados para o alto dos morros, dando origem às favelas no Rio, para as várzeas alagadiças em São Paulo e no Recife, onde se formam os mulambos (Marins 1998: 131-212).

O quadro que se descortina a partir daí parece, literalmente, apresentar-se em branco e preto. Todo o esplendor do palco é assumido pela elite branca, num espetáculo de ostentação onde não estão previstos personagens não-europeus. Não apenas os negros e seus descendentes são excluídos da cena pública, mas também todo o conjunto de suas festas, rituais e práticas habituais são postos na ilegalidade. Danças 
com tambores, desfiles de máscaras e serestas de violão são denunciadas e perseguidas por toda a cidade. Templos são invadidos, os fiéis presos, os instrumentos musicais confiscados, objetos de culto e adornos seqüestrados pela polícia, quando não destruídos no próprio local. A intenção precípua das autoridades era retirar da sociedade urbana gente que se pretendia identificar com o barbarismo, a indigência, a embriaguez, a sensualidade e o crime (Sevcenko 1998: 7-48).

A exclusão obviamente atinge também as instituições culturais, os meios de comunicação e a vida intelectual. São extremamente raros os documentos desse período em que fique manifesta alguma intenção séria de retratar as condições de vida, quanto mais as tradições culturais dos grupos marginalizados. Do ponto de vista das autoridades oficiais, empenhadas num amplo esforço de reforma urbana e sanitária, tratava-se de eliminar o que um chefe de polícia do Rio de Janeiro descreveu como "a imundíce e as fezes sociais" (Sevcenko 1993: 70-2). Tratava-se de eliminar essas presenças tanto do contexto da cidade, quanto das bibliotecas, dos arquivos e do debate público em geral. Um desígnio perverso, cujo sucesso as enormes dificuldades para a pesquisa histórica atual infelizmente confirmam.

Havia entretanto um pequeno nicho da vida cultural, que por sofrer também um sistemático processo de segregação, haveria de encontrar pontos em comum e estabelecer laços de solidariedade com esse grande contingente dos excluídos. Eram os membros da declinante boemia artístico-literária, ativa particularmente no Rio de Janeiro, onde haviam se concentrado os principais jornais, revistas e editoras durante o período imperial. Eles constituíam um grupo de jornalistas, escritores, ilustradores e cartunistas que, tendo militado ativamente pela Abolição e a República, na expectativa da constituição de uma sociedade democrática, haviam sido progressivamente alienados do processo de mudanças, conduzido no sentido de um regime plutocrático, autoritário, corrupto e assinalado por uma cruel desigualdade e opressão social.

Seu tom portanto era sempre polêmico e de crítica acerba à nova ordem republicana, transitando da sátira à diatribe e preconizando a reforma política e a redenção social. Ironicamente, esses intelectuais marginalizados eram aqueles que mantinham a mais fina sintonia com as tendências culturais da modernidade, numa interlocução 
conseqüente com seus confrades europeus. Não raro, ademais, seus mais lídimos representantes eram negros ou descendentes de linhagens africanas ou indígenas, como era o caso de Cruz e Souza, Machado de Assis, Euclides da Cunha, Lima Barreto ou João do Rio. Eram nesse sentido, gente duplamente marginalizada e estrategicamente posicionados para compreender as modalidades e as linhas internas da exclusão social e cultural na sociedade brasileira. Eram, poderíamos dizer, kalungas internos, transitando no sentido inverso da ventura, em direção ao inferno social brasileiro (Sevcenko 1995: 51-67).

Suas obras representam, nesse sentido, fontes privilegiadas para penetrar nos meandros mais esconsos da cena muda das metrópoles florescentes. A principal chave para a interpretação de seus textos é aquela que articula simultaneamente alteridade, exclusão e modernidade (Sevcenko 1998: 522-4). Ou seja, era pelo ardil do habilidoso domínio dos recursos da sintaxe moderna, que eles conseguiam escapar do círculo onipresente da exclusão em que se encontravam circunscritos. Exibindo os signos da nova era que a burguesia arrivista tanto ambicionava, abriam trilhas para infiltrar sua crítica implacável contra a ordem vigente. Era esse o sentido do sarcasmo de Machado de Assis. Em uma de suas crônicas ele conduz uma comparação patética entre as tensões sociais agudas que afligiam o país e o otimismo pífio da cultura dominante, deslumbrado com as últimas novidades do mercado:

"Quem põe o nariz fora da porta, vê que esse mundo não vai bem. A agência Havas é melancólica. Todos os dias enche os jornais de uma torrente de notícias que, se não matam, afligem profundamente [...] Por isso digo que o mundo não vai bem, e desconfio que há algum plano divino, oculto aos olhos humanos. Talvez a terra esteja grávida. Que animal se move no útero dessa imensa bolinha de barro, em que nos despedaçamos uns aos outros? Não sei; pode ser uma grande guerra social, nacional, política ou religiosa, uma deslocação de classes ou de raças, um enxame de idéias novas, uma invasão de bárbaros, uma nova moral, a queda dos suspensórios, o aparecimento dos autos." (A Semana, Rio, 06/10/1895)

O texto de Michel de Certeau sobre a história do cotidiano é útil em particular para compreender essa prática, comum aos destituídos, de incorporar clandes- 
tinamente elementos do universo do privilégio, tanto no sentido material quanto simbólico. Ele o define através das conotações de origem medieval da prática do pouching. Pressionados pela fome e a carência de terras, os camponeses invadiam, perpetrando pequenos mas sistemáticos saques às grandes reservas de caça e coleta dos mansos senhoriais. As conseqüências naturalmente eram trágicas para quem fosse pego, mas a grande arte do pouching consiste em nunca deixar-se pegar, em especializar-se na ação clandestina, como a prática decisiva para garantir a sobrevivência num cotidiano em que todas as injunções estão contra os desfavorecidos (De Certeau 1987: 45-8).

Numa realidade social de ingentes disparidades como a da América Latina como um todo, o pouching se torna a instituição informal decisiva da reprodução do cotidiano das classes populares (Sevcenko 1998).

Nesse sentido é particularmente reveladora a obra de João do Rio. Em suas crônicas ele se travestia de repórter da cidade, perscrutando os desvãos mais obscuros da capital, as áreas que estavam para além dos umbrais da urbes regenerada pela elite republicana, ou mesmo âmbitos ocultos em que nos recônditos da privacidade, do segredo e da surdina, membros das camadas privilegiadas se regozijavam na quebra das regras férreas a que submetiam a sociedade em geral. No contexto da imprensa do início do século ele foi por isso o grande inovador, inspirado na agilidade do moderno jornalismo francês, em particular Jean de Loraine de quem incorporou o pseudônimo, ele era louvado e imitado não apenas na busca das temáticas ousadas, inspiradas no vórtice das diferenças sociais e culturais da metrópole, mas sobretudo na criação de uma linguagem expressiva de alta comunicabilidade, baseada no fluxo vernacular, na criação de neologismos precisos e numa sintaxe franca, desenvolta, célere e de cortes rápidos. Por tudo isso João do Rio era amplamente reconhecido como a própria voz da modernidade, desde o início do século até sua morte precoce no começo dos anos 20. (Antelo 19 97: 9-35)

A questão que ele sempre busca sondar, em suas crônicas ou romances, é a do colapso dos quadros de valores que por séculos sustentaram e legitimaram a civilização européia, sorvidos que foram no vácuo gerado pela avassaladora transforma- 
ção tecnológica de fins do século 19. Num país de estrutura arcaica, baseado numa economia agrária, esses produtos e potenciais tecnológicos eram avidamente absorvidos e assimilados como manifestações prodigiosas, autênticas epifanias que comprovavam a entrada do Brasil numa ordem cosmopolita, promissora de recursos, opulências e esperanças nunca dantes imaginadas. Não lhe interessava entretanto essa percepção mirífica dos aparatos da modernidade, tão louvados pela imprensa e intelectuais conservadores. O que o atraia era revelar o equívoco dessa enorme ilusão, o arrebatamento com que as elites se apegavam a essa falácia como um sucedâneo à sua incapacidade de transformar as estruturas retrógradas do país e o uso que faziam das virtualidades tecnológicas ao mesmo tempo como um recurso para legitimar sua preponderância social e para ampliar sua capacidade de controle compulsório sobre toda a sociedade (Sevcenko 1998: 513-619).

Outra das linhas de sua arte, aquela que mais particularmente nos interessa neste momento, era sua percepção aguçada de como esse mesmo efeito também ocorria no sentido inverso. Ou seja, como membros dos grupos subalternos se apropriavam de símbolos dessa mesma modernidade a fim de utilizá-los em seu próprio proveito, com vistas a ampliar seu quadro de alternativas e possibilidades de sobrevivência ou até mesmo de promoção social. O que observamos aqui, são os grupos subalternos fazendo o pouching nas ilusões modernizantes das elites e, aos poucos mas sistematicamente, irem saqueando suas fantasmagorias modernistas.

Assim, por exemplo, se um dos símbolos mais espetaculares da vida moderna são os esportes e os clubes desportivos, com suas rigorosas regras de exclusividade e seleção, ele percebe como são sobretudo elementos dos grupos marginalizados, incluindo negros e seus descendentes, quem logo se destaca nesses esportes, quebrando a rigidez das normas excludentes. Como em sendo o automóvel a mais celebrada, desejada e glorificada dádiva da cidade moderna, serão os jovens imigrantes italianos, filhos de operários anarquistas, quem se tornarão os choffeurs e mecânicos mais famosos e bem remunerados do Rio de Janeiro. Também no que se refere à música e às danças populares, a nova fonte rítmica e energética da vida cultural, graças à indústria fonográfica, os maiores expoentes dentre os compositores, intérpretes e 
dançarinos vinham das camadas subalternas, com enorme destaque para os negros e seus descendentes. Ironicamente eram dentre os mais excluídos, perseguidos e malignados que se encontravam as autênticas fontes da modernidade, tão sôfrega mas futilmente ansiadas pelas elites retrógradas (Sevcenko idem, ibidem).

Particularmente instigantes são as crônicas-reportagens que levam João do Rio a envolver-se com os recantos mais reservados da comunidade negra, deliberadamente mantidos secretos e bloqueados, como medida defensiva contra a intervenção destrutiva e criminalizadora da autoridade pública. Aqui não se trata mais de práticas de pouching, voltadas contra os âmbitos do privilégio, mas ao contrário, da preservação zelosa do que se sabia ser um tesouro precioso, ameaçado pela gana de saque do inimigo. Era nesse sentido que a comunidade negra mantinha redes clandestinas de templos, altares e santuários, em relação aos quais se adotavam todas as precauções para que apenas os iniciados tivessem acesso ou soubessem da sua existência.

O caso é dos mais interessantes, visto que suas raízes se aprofundam para as origens da sociedade colonial. Seu fundamento são dois fatos básicos. O primeiro, que os brancos escravistas e colonizadores jamais conheceram ou manifestaram qualquer remoto interesse em compreender as línguas e culturas dos povos africanos dominados. A rigor eles não tinham nenhuma, eram selvagens pura e simplesmente, idólatras em algum sentido demoníaco, sendo sua escravização uma oportunidade favorável para a conversão à religião e cultura cristãs. $\mathrm{O}$ outro fato básico, era o permanente terror de revolta escrava, o que levava as autoridades colonais a favorecerem a agregação de grupos de comunidades diferentes, no sentido de incentivar rivalidades e a tolerância às festas e danças de tambores, desde que associadas a crenças e divindades cristãs. Dessa dupla situação resultou que no interior da comunidade negra sempre prevaleceu um duplo padrão: em público manifestar apego à religião cristã católica, mas na privacidade preservada por rigorosos rituais de segredo, silêncio e clandestinidade, manter o culto de suas tradições sagradas, a devoção extática dos malungas dos grupos bantos ou dos orishas dos iorubas, por exemplo. Como a ignorância dos brancos sobre as culturas negras era absoluta, eles puderam manter todo seu repertório sagrado de ritmos, danças, colares, adereços, 
códigos de tecidos, de cores, marcas, tatuagens, objetos alegóricos e línguas rituais, sem que nunca seus dominadores suspeitassem de suas convicções católicas.

Havia contudo uma exceção. Era a suspeita dentre os colonizadores, de que alguns negros renegados praticassem feitiçaria. A desconfiança se baseava no fato óbvio de que os negros tinham um conhecimento extremamente elaborado da flora, tanto africana quanto em pouco tempo da brasileira, sobretudo graças ao concurso de sua convivência com indígenas cativos. Dado o seu completo desconhecimento das culturas da África e considerando seu permanente estado de receio e alarme contra vinganças e revoltas, era natural que criassem o fantasma do feitiçeiro todo poderoso, construído a partir do modelo europeu, e o projetassem contra os escravos que desfrutassem de maior respeito e autoridade espiritual em sua comunidade.

Essa imagem foi ampliada enormemente em fins do século 19, quando as transformações econômicas que inviabilizariam a escravidão como forma de exploração do trabalho concorriam para desorganizar as fazendas baseadas na mão de obra servil. Nesse contexto, o caos se instaura, as sedições pululam, os negros escravos se aproveitam das facilidades das ferrovias para fugir das fazendas e se reunir aos contingentes cada vez maiores de quilombos, comunidades de fugitivos que se autodeclaravam livres. Difundiu-se então o terror de uma grande revolta geral de escravos, a qual culminaria num massacre de brancos no estilo haitiano. Os líderes dessa presumida rebelião, nesse apocalipse afantasmado de uma classe escravocrata que via seu mundo dissolver-se como fumaça, seriam naturalmente os feiticeiros negros (Machado 1994; Wissenbach 1998; Macedo 1988).

O caso de João do Rio é especialmente interessante porque ele foi um dos primeiros representantes da cultura de linhagem européia a penetrar no âmbito secreto da comunidade negra, ou pelo menos em alguns nichos isolados desse mundo clandestino. Além de procurar ali o contato com músicos, tocadores de tambores rituais, sambistas, fazedores de altares e festeiros, o repórter da modernidade, como não poderia deixar de ser, foi atrás dessa figura mitológica por excelência, o "feiticeiro negro". O que de fato não foi tarefa difícil, pois conforme ele constatou: 
"os feiticeiros formigam no Rio, espalhados por toda a cidade, do cais à Estrada de Santa Cruz" (Rio 1976: 35).

Assim que se infiltra no território da cultura negra, de dentro das casas dos líderes espirituais, dos altares e terreiros, o repórter estabelece uma espécie de olhar estrábico, por via do qual por um lado observa a cena local e por outro analisava atentamente o comportamento da elite branca em relação àqueles espaços e símbolos. Eé essa mirada ambivalente que lhe permite compreender a articulação daqueles dois mundos mantidos à parte por uma fronteira de repressão violenta. O que ele vê então o estarrece:

"Eu vi senhoras de alta posição saltando, às escondidas, de carros de praça, como nos folhetins de romances, para correr, tapando a cara com véus espessos, a essas casas; eu ví sessões em que mãos enluvadas tiravam das carteiras ricas notas e notas aos gritos dos negros malcriados que bradavam.

- Bota dinheiro aqui!

Tive em mãos, com susto e pesar, fios longos de cabelos de senhoras que eu respeitava e continuarei a respeitar nas festas e nos bailes, como as deusas do Conforto e da Honestidade. Um babalorixá da costa da Guiné guardou-me dois dias às suas ordens para acompanhá-lo aos lugares onde havia serviço, e eu o ví entrar misteriosamente em casas do Botafogo e da Tijuca, onde, durante o inverno, há recepções e conversationes às 5 da tarde como em Paris e nos palácios da Itália. Alguns pretos, bebendo comigo, informavam-me que tudo era embromação para viver e, noutro dia, tílburis paravam à porta, cavalheiros saltavam, pelo corredor estreito desfilava um resumo da nossa sociedade, desde os homens de posição, às prostitutas derrancadas, com escala pelas criadas particulares. (...)" (Rio 1976: 40).

Não escapava a João do Rio o fio que enredava o ápice da sociedade com a sua parte maldita na mesma teia de paixões. A transição do regime monárquico para o republicano fora marcada por um intenso processo de fraudes financeiras, manobras especulativas de todo gênero, favorecimentos ilícitos e açambarcamentos, os quais promoveram a queima das grandes fortunas imperiais, abrindo o caminho para ascensão de uma nova camada de argentários arrivistas. A essa camada ascendente, cujas origens oscilavam entre o nebuloso e o francamente criminoso, foi atribuído o ambíguo epíteto de "homens novos", não só pela sua condição de recém-chegados 
à cena social, mas por surgirem nela como os portadores de uma moralidade inteiramente adaptada à febre especulativa e manipulatória em pleno vigor, e que foi assim resumida pela ironia de Machado de Assis:

"Mete dinheiro na bolsa - ou no bolso, diremos hoje - e anda, vai para diante, firme, confiança na alma, ainda que tenhas feito algum negócio escuro. Não há escuridão quando há fósforos. Mete dinheiro no bolso. Vende-te bem, não compres mal aos outros, corrompe e sê corrompido, mas não te esqueças do dinheiro, que é com que se compram os melões. Mete dinheiro no bolso (...) Make money. E depressa, depressa, antes que o dinheiro acabe" (A Semana 02/08/1896).

Num meio tão volátil, de posições e futuro incertos, em que os agentes econômicos e as lideranças políticas eram elas mesmas obscuras, suspeitas e de moralidade equívoca por convicção, era mais que natural a vida ser encarada como uma grande jogatina, cujas influências mais providenciais eram o acaso e a esperteza. Não por acaso a mais sólida instituição do Rio de Janeiro do começo do século tornou-se o “jogo do bicho", uma loteria clandestina baseada num código cifrado de números e animais, que galvanizava a imaginação e os bolsos da população por todos os quadrantes da cidade e através de todas as classes e camadas, condições e etnias (Herschmann e Lerner 1993).

João do Rio observa como a antiga imagem maligna do feiticeiro, dos dias da crise do sistema escravista e da grande ameaça da anarquia social, se transfigurava agora em meio ao afã arrivista no guia todo-poderoso, no Merlin com o socorro do qual se seria capaz de vencer o dragão, abater o inimigo, conquistar a donzela, herdar o castelo e deitar-se sobre o tesouro. Ironicamente porém, esse mago onipotente é o ser mais miserável e perseguido do meio social. Fato inusitado que permite um surpreendente sistema de trocas: os arrivistas projetam suas inseguranças e desejos incontroláveis sobre os líderes negros e esses colonizam a mente daqueles para obterem recursos, salvaguardas e alternativas com as quais, de outro modo, jamais poderiam sequer sonhar.

"Toda essa gente vive bem, à farta, joga no bicho como Oloô-Tetê, deixa dinheiro quando morre, às vezes fortunas superiores a cem contos, e achincalha o nome 
de pessoas eminentes da nossa sociedade, entre conselhos às meretrizes e goles de paratí. As pessoas eminentes não deixam entretanto de ir ouví-los às baiúcas infectas, porque os feiticeiros que podem dar riqueza, palácios e eternidade, que mudam à distância, com uma simples mistura de sangue e de ervas, a existência humana, moram em casinholas sórdidas, de onde emana um nauseabundo cheiro." (Rio 1976: 36).

Considerando dessa perspectiva o mito cabinda que vimos no início, do branco que invade a África, mata o babalâ, sequiestra o rei, rouba-lhe todos os segredos mágicos, executa a rainha e se vai deixando um lastro de escravidão e saque, chegamos agora a uma completa inversão. São os "homens novos", agentes da instauração da irracionalidade como sistema, que elegem os "feiticeiros negros" tanto como tutores espirituais, premidos pela angústia de sua cupidez e precariedade, como também como instrumentos de sua disposição de beneficiar-se a qualquer custo, em especial graças à ruína de tudo e todos ao redor. Nesse seu paroxismo egoísta e anti-social, a nova elite provê a essa população marginalizada (no sentido em que os líderes espirituais e os templos operavam como centros de agregação comunitária), paradoxalmente, uma das únicas formas que disporiam de apoio econômico, convivência dentre círculos diversificados da sociedade e respeito moral. Retorno do reprimido, o babalâ̂ recuperou o segredo do feitiço em posse do branco e renegociou os termos da dominação. Esse processo poderia ser figurado como a troca da magia tradicional pelo pouching dos símbolos da cultura dominante ${ }^{1}$.

Uma última questão sugerida por essa linha de reflexões se refere ao modo como João do Rio conseguiu penetrar para além das fronteiras de sua própria cultura. A questão é relevante pois requer que se considere até que ponto ele não saqueou essa cultura pura e simplesmente para seus próprios interesses e fins, num ato semelhante ao homem branco do mito cabinda. E de fato, como vimos, em parte ele se infiltra

\footnotetext{
${ }^{1}$ Esse mesmo mecanismo seria reencetado inúmeras vezes, em outros momentos e noutras direções, envolvendo, por exemplo, o samba, o carnaval e os desfiles de escola de samba, a partir da tutela política de Getúlio Vargas.
} 
nas sociedades secretas para assistir ao conluio clandestino entre aquele mundo execrado e os mesmos agentes responsáveis pela sua execração. Sua intenção, portanto, é produzir uma crítica acerba da ordem social e moral espúria criada pelo regime republicano e expôr toda a pletora de seus preconceitos, sua indisposição à solidariedade e a qualquer ato de comunhão ou mesmo comunicação com o diverso.

Mas não era só. Para penetrar naqueles meios fechados, João do Rio contava com um intermediário, ao mesmo tempo guia, tradutor e quem fazia as apresentações necessárias, um jovem negro que ele identifica apenas parcialmente (por razões de segurança sobretudo, mas também para preservar algum espaço para a elaboração ficcional do personagem), como António. Esse rapaz era um caso excepcional, tendo sido educado no Rio de Janeiro e em Lagos, na Nigéria, tendo portanto uma cultura híbrida. Conhecia as tradições do catolicismo, das comunidades ioruba e das haussa islamizadas. Era nesse sentido um guia ideal, mas também problemático, pois embora tivesse grande experiência de convívio religioso com os três grupos, seu compromisso maior era com os aspectos mais modernos da vida urbana carioca. Daí sua colaboração com o escritor-repórter e o prazer de desfilar com ele pelos bulevares e bares elegantes da cidade. O mesmo prazer que João do Rio tinha de ser visto junto com seu jovem amigo pelos becos escuros e fréges da Cidade Nova, Saúde e Gamboa. Ambos portanto compartilhavam de interesses recíprocos e enriqueciam um a experiência do outro. E se António mostrou ao repórter o parasitismo dos arrivistas em relação aos cultos negros, propiciou-lhe também o convívio de experiências místicas da mais profunda autenticidade nos redutos secretos da comunidade negra. (Rio 1976: 19-54).

Esse caso parece configurar um quadro de interação generosa e criativa de diferentes vozes culturais, constituindo aquela forma de experiência fraternitária que Hans-Georg Gadamer denomina de "tradição":

"Nossa consciência histórica é sempre preenchida por uma variedade de vozes dentre as quais o eco do passado se faz ouvir. Só no caráter multifário dessas vozes é que esse passado se manifesta. Essa constitui a natureza da tradição da qual queremos compartilhar e com a qual nos integramos. A própria pesquisa histórica 
moderna não se resume a um mero trabalho de pesquisa, mas é acima de tudo a intermediação da tradição.” (Risser s/d: 55).

A descrição que João do Rio faz, por exemplo, da entrada dos cordões de negros, atravessando ousadamente as zonas de segregação e anunciando o início do carnaval nas ruas da cidade, serve quase que como um desdobramento do argumento acima.

"O cordão é o Carnaval, o cordão é vida delirante, o cordão é o último elo das religiões pagãs. Cada um desses pretos ululantes tem, por sob a belbutina e o reflexo discrômico das lantejoulas, tradições milenares; cada preta bêbada, desconjuntando nas tarlatanas amarfanhadas os quadris largos, recorda o delírio das procissões em Biblos pela época da primavera e a fúria rábida das bacantes. Eu tenho vontade, quando os vejo passar zabumbeando, chocalhando, berrando, arrastando a apoteose incomensurável do Rumor, de os respeitar, entoando em seu louvor a 'prosódia' clássica com as frases de Píndaro: salve grupos floridos, ramos floridos da vida... (...) E por isso adoro os cordões, a vida paroxismada, todos os sentimentos tendidos, todas as cóleras a rebentar, todas as ternuras ávidas de torturas... (...) O Carnaval teria desaparecido, (...) se não fosse o entusiasmo dos grupos da Gamboa, do Saco, da Saúde, de São Diogo, da Cidade Nova, esse entusiasmo ardente que meses antes dos três dias vem queimando como pequenas fogueiras crepitantes para acabar no formidável e total incêndio que envolve e estorce a cidade toda. Há em todas as sociedades, em todos os meios, em todos os prazeres, um núcleo dos mais persistentes, que através dos tempos guarda a chama pura do entusiasmo. (...) Os cordões são os núcleos irredutíveis da folia carioca, brotam como um fulgor mais vivo e são antes de tudo bem do povo, bem da terra, bem da alma encantadora e bárbara do Rio.” (Rio 1976: 229-30).

Esse texto nos permite encerrar retornando ao conceito de "preservação", entendido como o contraponto do ato político do pouching e entalhado aqui na sua forma conceitual mais cristalina e eticamente implicada nas palavras de Gadamer:

"Mesmo a mais genuína e pura tradição não persiste por inércia do que já existiu antes. Ela deve ser afirmada, abraçada, cultivada. Ela é, essencialmente, preservação (Bewahrung), e é um elemento ativo de todo processo de mudança histórica. Mas embora a preservação seja um ato da razão, ela não é em absoluto um ato conspícuo. Esse é o motivo pelo qual só a inovação e o planejamento 
parecem ser o resultado da razão. Isso no entanto é uma ilusão. Mesmo onde a vida muda de forma violenta, como em épocas de revolução, muito mais do que é antigo é preservado, na suposta transformação total, do que em geral se julga, e aquilo que é mantido se combina com o que é novo, reformulando os quadros de valores. Assim, em todos os sentidos, a preservação constitui um ato de escolha livre como o são a renovação e a revolução." (Risser s/d: 71).

Essa foi a sabedoria que faltou ao homem branco que esbulhou a mágica dos cabindas na África. Sorte nossa que eles souberam recuperá-la no Novo Mundo, tomando de assalto a modernidade.

\section{Referências Bibliográficas}

ANTELO, Raul. "Introdução" In: JOÃO DO RIO, A Alma Encantadora das Ruas. São Paulo, Cia. das Letras, 1997.

ASSIS, Machado de. "Crônica" In: A Semana, Rio, 06/10/1895.

DE CERTEAU, Michel. Cotidiano e História. São Paulo, Brasiliense, 1987.

HERSCHMANN, M. e LERNER, K. Lance de Sorte: o futebol e o jogo do bicho na Belle Époque carioca. Rio, Diadorim, 1993.

MACEDO, Joaquim Manuel de. As Vítimas-Algozes, quadros da escravidão. São Paulo, Scipione, 1988.

MACHADO, Maria Helena. O Plano e o Pânico, os movimentos sociais na década da Abolição. São Paulo, Edusp, 1994.

MARINS, Paulo C. Garcez. "Habitação e Vizinhança: limites da privacidade no surgimento das metrópoles brasileiras" In: SEVCENKO, N. (org.) História da Vida Privada No Brasil, vol. 3, São Paulo, Cia. das Letras, 1998, pp. 131-212.

MOURA, Roberto. Tia Ciata e a Pequena África do Rio de Janeiro. Rio, Departamento Geral de Informação e Documentação Cultural, Secretaria da Cultura, 1995.

RIO, João do. As Religiões do Rio. Rio de Janeiro, Nova Aguilar, 1976.

RISSER, James. Hermeneutics and the Voice of the Other. New York, State University of New York Press, p. 55. 
SEVCENKO, Nicolau. "A Capital Irradiante: técnica, ritmos e ritos do Rio" In: História da Vida Privada no Brasil, vol 3, pp. 522-4.

."The Hermeneutics of daily life", paper apresentado no Center for Latin American Cultural Studies, King's College, University of London, February, 1998, cópia digitada.

A Revolta da Vacina: mentes insanas em corpos rebeldes. São Paulo, Scipione, 1993.

Literatura Como Missão, tensões sociais e criação cultural na Primeira República. São Paulo, Brasiliense, 1995.

SLENES, Robert W. “ 'Mulungu, Ngoma vem!' África encoberta e descoberta no Brasil” In: Cadernos Museu Escravatura, Luanda, Museu Nacional da Escravatura, Ministério da Cultura, 95, pp. 9-11.

WISSENBACH, M. C. Cortez. Sonhos Africanos, Vivências Ladinas. São Paulo, Hucitec, 1998. 